\title{
A CONTROLLED TRIAL OF IMMEDIATE AND DELAYED CLOSURE OF SPINA BIFIDA CYSTICA
}

\author{
BY \\ W. JOHN W. SHARRARD, ROBERT B. ZACHARY, JOHN LORBER \\ and ANNE M. BRUCE \\ From the Children's Hospital, Sheffield, and the Department of Child Health, University of Sheffield
}

(RECEIVED FOR PUBLICATION OCTOBER 15, 1962)

A child born with spina bifida cystica faces the multiple and serious hazards of meningitis, hydrocephalus, paralysis and deformity of the lower limbs, and urinary bladder paralysis and its consequences. In the past, the absence of any effective treatment for hydrocephalus encouraged many surgeons and paediatricians to adopt an expectant policy in the management of spina bifida cystica. In children with myelomeningocele the mortality from hydrocephalus and meningitis was over $90 \%$.

The development of antibiotics to assist the control of meningitis, and the advent of the Holter valve for the control of hydrocephalus have so greatly altered the immediate prognosis that even a child with an extensive myelomeningocele must be considered to have a good chance of survival (Lorber, 1961a). Serious thought must therefore be given to the best management of the spinal defect, particularly with regard to the paralysis that was previously a secondary consideration.

A retrospective survey of the degree of paralysis of the lower limbs in 386 children aged between 1 and 9 years, most of whom had originally had a myelomeningocele suggested that muscle innervation was preserved better in those treated by immediate closure of the myelomeningocele than in those in whom conservative treatment or delayed closure had been undertaken (Sharrard, 1962). In view of these findings, and the lack of unanimity of surgical opinion about the optimum time for closure of a myelomeningocele, we decided to conduct a controlled trial of immediate and delayed or no closure.

\section{Method}

As from October 1961, all infants admitted to the hospital within $\mathbf{4 8}$ hours of birth suffering from myelomeningocele of which part or all of the defect was situated in the napkin area were included in the study. Infants with pure meningocele were excluded. The only other exclusions were three children with such poor general condition, owing to intracranial haemorrhage or to respiratory distress syndromes, that operative intervention was contraindicated. Infants were allocated to operative or non-operative treatment by random sampling. This sampling was determined before the child's admission. Apart from the operation, management of the two groups was identical. Both were given the same prophylactic antibiotics, namely tetracycline with amphotericin B (mysteclin F) and neomycin. When specific infection developed, other appropriate antibiotic agents were used. Air ventriculograms were carried out on all cases to determine the grade of hydrocephalus present (Lorber, 1961 b), and when surgical treatment for hydrocephalus was necessary it was the same in both groups.

All the assessments were made by the same team. The operations were performed by the same surgical team and the medical treatment was given by the same paediatric team. The operation was done as an emergency. The thin membrane around the plaque of nervous tissue was removed; the dura was incised at the extreme edge of the defect, dissected up and sutured over the plaque to form a tube. Sometimes an extra fascial flap was formed from the lumbar fascia. The skin was mobilized and a direct suture was undertaken without swinging any skin flaps. In the non-operative group. a sterile dressing was applied and covered by waterproof adhesive strapping to try to prevent faecal or other contamination of the area.

All the patients were assessed as soon as possible after admission and at appropriate intervals thereafter. The trial ended in March 1962 after 40 patients had been included, on 20 of whom immediate operative treatment was carried out.

\section{Comparability}

The sites of the spina bifida were equally distributed in the two groups (Table 1). In the operated group. there were three sacral myelomeningoceles, as compared with one in the unoperated group. In the cases with a sacral lesion only, the paralysis of the lower limbs was minimal. There was, however, a greater number of thoracolumbar lesions in the operative group, and in these the paralysis was severe.

The incidence of hydrocephalus was the same in both groups. There was only one patient in each group 
TABLE 1

COMPARABILITY

\begin{tabular}{|c|c|c|c|c|c|}
\hline & & & & $\begin{array}{l}\text { Operative } \\
\text { Group } \\
\text { (20 cases) }\end{array}$ & $\begin{array}{c}\text { Non-operative } \\
\text { Group } \\
\text { (20 cases) }\end{array}$ \\
\hline $\begin{array}{l}\text { Site of spina bifida } \\
\text { Thoraco-lumbar } \\
\text { Lumbar . } \\
\text { Lumbo-sacral } \\
\text { Sacral . . }\end{array}$ & $\begin{array}{l}\text { cystic } \\
\cdots \\
\cdots \\
\cdots \\
\cdots\end{array}$ & $\begin{array}{l}\text { ca: } \\
\quad \cdots \\
\quad \cdots \\
\quad \cdots \\
\quad \cdots\end{array}$ & $\begin{array}{l}\cdots \\
\cdots \\
\cdots\end{array}$ & $\begin{array}{l}7 \\
6 \\
4 \\
3\end{array}$ & $\begin{array}{l}4 \\
9 \\
6 \\
1\end{array}$ \\
\hline $\begin{array}{c}\text { Hydrocephalus: } \\
\text { None } \quad \ldots \\
\text { Grade I } \ldots \\
\text { Grade II } \ldots \\
\text { Grade III } \\
\text { Unknown } \\
\begin{array}{c}\text { gram } \\
\text { gram) }\end{array}\end{array}$ & $\begin{array}{l}\ldots \\
\cdots \\
\cdots \\
\text { ino } \\
\ldots\end{array}$ & $\begin{array}{c} \\
\ldots \\
\ldots \\
\ldots \\
\text { ventriculo } \\
\ldots\end{array}$ & $\begin{array}{l}\cdots \\
\cdots \\
\cdots \\
\cdots\end{array}$ & $\begin{array}{l}1 \\
2 \\
7 \\
4 \\
6\end{array}$ & $\begin{array}{r}1 \\
1 \\
10 \\
3 \\
5\end{array}$ \\
\hline $\begin{array}{l}\text { Age at initial exam } \\
\text { Range }\end{array}$ & $\begin{array}{l}\text { inatio } \\
\ldots \\
\ldots\end{array}$ & $\begin{array}{c}\text { on (hours } \\
\ldots \\
\cdots\end{array}$ & $\begin{array}{l}\text { ): } \\
\cdots \\
\cdots\end{array}$ & $\begin{array}{l}2-32 \\
15 \cdot 8\end{array}$ & $\begin{array}{l}3-48 \\
16 \cdot 1\end{array}$ \\
\hline $\begin{array}{cc}\text { Initial muscle score } \\
\text { Range } & \ldots \\
\text { Average } & \ldots\end{array}$ & $\begin{array}{l}\text { e: } \\
\cdots\end{array}$ & 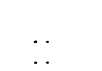 & $\begin{array}{l}\ldots \\
\ldots\end{array}$ & $\begin{array}{l}0-70 \\
26 \cdot 4\end{array}$ & $\begin{array}{l}0-70 \\
35 \cdot 5\end{array}$ \\
\hline
\end{tabular}

without hydrocephalus and the severity of the hydrocephalus in the others was of the same order in both groups. The average age of the infants at the initial examination and muscle assessment was the same in both groups. The mean age in the operated group was 15.8 hours, with a range of 2 to 32 hours, and $16 \cdot 1$ hours in the unoperated group, with a range of 3 to 48 hours. The general level of muscle paralysis in the lower limbs was comparable in the two groups, though the unoperated group showed somewhat less paralysis at the initial examination.

\section{Neurological Assessment of Muscle Activity}

Those who have experience of attempting muscle assessment in young children may well be inclined to be sceptical about its value. In children between the ages of 1 and 4 years accurate muscle charting may be difficult and have to be repeated, but it is easy in a newborn baby or in infants during the early months of life. It can

TABLE 2

FUNCTIONAI. GRADES OF PARALYSIS

\begin{tabular}{|c|c|c|}
\hline Grade & $\begin{array}{l}\text { Muscle Score } \\
\text { (Max. 70) }\end{array}$ & Function \\
\hline 0 & $0-9$ & $\begin{array}{l}\text { Complete paralysis; no expectation } \\
\text { of walking }\end{array}$ \\
\hline 1 & $10-19$ & $\begin{array}{l}\text { Severe paralysis; possibly may } \\
\text { walk with extensive supports }\end{array}$ \\
\hline 11 & $20-39$ & $\begin{array}{l}\text { Moderate paralysis; possibly may } \\
\text { walk with some aids after recon- } \\
\text { structive operations }\end{array}$ \\
\hline III & $40-59$ & $\begin{array}{l}\text { Mild paralysis; probably will walk } \\
\text { with minimal aids or indepen- } \\
\text { dently after minor reconstructive } \\
\text { operations }\end{array}$ \\
\hline IV & $60-$ & $\begin{array}{l}\text { Normal or near normal; should } \\
\text { walk independently }\end{array}$ \\
\hline
\end{tabular}

readily be seen that a newborn baby, when awake, uses every muscle in his lower limbs. Similarly, there is no difficulty in examining infants with paralytic lesions. Each main muscle group was assigned a muscle grade on the scale recommended by the Medical Research Council (1942). To check this assessment, further examinations were made in the surviving children at intervals after the first month, without reference to any previous assessment.

Direct electrical stimulation, nerve conduction stimulation and electromyography tests were made in some cases. When done within a few hours of birth, these tests often showed interesting contrasts with clinical observations of muscle activity. A positive response to stimulation of short duration or to nerve conduction stimulation was sometimes present not only in muscles that showed voluntary activity but also in muscles that showed no voluntary activity at all. When tests were repeated in infants after 1 month of age, however, the results almost always accorded with the clinical observations.

It is sometimes suggested that voluntary movement cannot be distinguished from reflex movement in infants during the early weeks of life. From earlier observations it was known that children who had developed infection of the myelocele plaque, or severe hydrocephalus, or who had diastematomyelia, might show sparse or absent voluntary movement but considerable reflex movements, usually of a withdrawal type, on stimulation of the skin of the limbs. It was decided that any child in whom only this reflex type of response was obtained should be regarded as a child with paralysis, only true voluntary movements being acceptable. In all the $\mathbf{4 0}$ cases, there was only one who showed mainly reflex activity on the initial assessment soon after birth. All others showed muscle activity that was independent of stimulation of the lower limbs.

Assessments of muscle activity were made on admission, at the third week and at the third month. The mean level of paralysis in the lower limbs was determined by adding together the grades of power of seven muscle groups-hip flexors, hip adductors, glutei, quadriceps, hamstring muscles, ankle dorsiflexors and ankle plantar flexors. Each muscle group could score from 0-5, giving a maximum of 35 for each limb and a total score of 70 in a normal infant. Using these muscle scores, five grades of paralysis were defined (Table 2). Grade 0 represents a score from 0-9, Grade I a score from 10 to 19. Grade II a score from 20 to 39 , Grade III a score from 40 to 59 , and Grade IV a score of 60 or over.

A comparison of the muscle charts of the infants in this series with those of children treated earlier suggests that some functional significance can be assumed for the five grades of paralysis. Grade 0 indicates complete paralysis with no expectation of walking; Grade I, severe paralysis with the possibility of walking with the help of extensive support; Grade II, moderate paralysis with the possibility of walking with some aids after reconstructive operations; Grade III, mild paralysis with the probability of walking with minimal aids or independent walking after minor reconstructive operations and Grade IV, normal walkıng. 
TABLE 3

RESULTS

\begin{tabular}{|c|c|c|c|}
\hline & & $\begin{array}{l}\text { Operative } \\
\text { Group }\end{array}$ & $\begin{array}{l}\text { Non-operative } \\
\text { Group }\end{array}$ \\
\hline $\begin{array}{l}\text { Died .. } \\
\text { Local sepsis: }\end{array}$ & $\cdots$ & 9 & 12 \\
\hline Cases & $\cdots$ & 8 & 10 \\
\hline $\begin{array}{l}\text { Points (Grades 0-III) } \\
\text { Meningit is: }\end{array}$ & $\cdots$ & 13 & 19 \\
\hline $\begin{array}{lll}\text { Cases } & \ldots & \ldots \\
\text { Survivors } & \ldots & \ldots\end{array}$ & $\cdots$ & 5 & 8 \\
\hline $\begin{array}{l}\text { Duration of hospital st } \\
\text { vivors, average (days) }\end{array}$ & of sur- & 37 & 61 \\
\hline
\end{tabular}

\section{Results}

The results in the operative and non-operative groups are shown in Table 3.

Mortality. During the first admission, there were nine deaths in the operated group and 12 in the unoperated group. All the survivors were fit to be discharged home with the spinal defect healed. One further death occurred at home among the operated group.

Local Sepsis.-Local sepsis occurred in eight operated cases and 10 unoperated cases. On the basis of a rough classification into slight, severe and complete breakdown, the degree of sepsis was distinctly greater in the unoperated group. The causative organisms (Table 4) were varied, $P s$. pyocyaneus particularly affecting the unoperated group.

Meningitis and Ventriculitis. There were five cases of meningitis in the operated group and eight in the unoperated group with one survivor in each group. The causative organisms varied, but $P s$. pyocyaneus predominated in the unoperated group. It was insensitive to all antibiotic therapy.

Neurological Lesions. The most striking differences in the two groups were found in the neurological changes. The results are shown in histogram form. Fig. 1 shows the distribution of the five functional grades in the 20 operated and 20 unoperated cases at the initial assessment. The level of paralysis in both groups was more or less evenly distributed. If anything, the initial level of paralysis was slightly more severe in the operated group.

At the end of the third week, 14 of the 20 operated infants had survived. They were then assessed for the second time (Fig. 2). None of them showed any post-operative neurological deterioration. In three, the paralysis improved by one grade, in two by two
TABLE 4

CAUSATIVE ORGANISMS OF LOCAL SEPSIS AND OF MENINGITIS

\begin{tabular}{|c|c|c|c|c|c|}
\hline \multirow[b]{2}{*}{ Organism } & & \multicolumn{2}{|c|}{ Local Sepsis } & \multicolumn{2}{|c|}{ Meningit is } \\
\hline & & $\begin{array}{l}\text { Operated } \\
\text { (8 cases) }\end{array}$ & $\begin{array}{c}\text { Not } \\
\text { Operated } \\
\text { (10 cases) }\end{array}$ & $\begin{array}{l}\text { Operated } \\
\text { (5 cases) }\end{array}$ & $\begin{array}{c}\text { Not } \\
\text { Operated } \\
\text { (8 cases) }\end{array}$ \\
\hline Staph. aureus & $\ldots$ & 4 & 6 & - & - \\
\hline Ps. pyocyaneus & $\cdots$ & - & 5 & - & 5 \\
\hline Proteus . & $\ldots$ & 4 & 二 & 2 & i \\
\hline E. coli & $\because$ & 3 & 1 & 二 & 1 \\
\hline Staph. albus & . & - & - & 1 & - \\
\hline Strep. viridans & $\ldots$ & - & - & - & 1 \\
\hline Klebsiella.. & $\cdots$ & - & - & 1 & - \\
\hline Unknown. . & $\cdots$ & 2 & - & - & - \\
\hline
\end{tabular}

grades and in two by three grades. The remaining seven did not change, but these included three infants who were already in the highest grade of normal or near normal. As an example, one infant born with a lumbar myelomeningocele was seen six hours after birth. His hip flexors and sartorius were active (power 3 ) and the adductor gracilis was also working (power 2), but there was no evidence of other muscle activity. Electrical tests showed a good faradic response in the hip adductors, quadriceps, medial hamstrings, gluteus medius and all dorsiflexors of the feet. Three weeks later, there was normal voluntary action in both lower limbs in the hip flexors, adductors, quadriceps, sartorius, medial hamstrings, tibialis anterior, peroneus tertius and the toe extensors, all the muscles that had shown a response to faradism. Another child, first seen 12 hours after birth, only had hip flexors and sartorius acting (power 3 ) on both sides. Three weeks later, there was strong voluntary activity in every muscle in the lower limbs except gluteus maximus, lateral hamstring, calf and intrinsic muscles, but even these showed activity to power 2 or 3 . Four months later, the muscle chart was still the same. This child will undoubtedly be able to walk with minimal aids.

In the unoperated group, there were 18 infants who survived three weeks or more, and a second assessment was made at the end of the third week. The picture here was very different from the operated group (Fig. 3). In no case was there any improvement. At best, in nine the paralysis remained unchanged from the initial level and this quite often meant that the paralysis was already complete or almost complete and remained at that grade. In four infants the paralysis increased by one grade, in two by two grades and in three by three grades. For example, one infant was examined eight hours after birth; all muscles in both lower limbs were acting normally except for the calf and intrinsic 


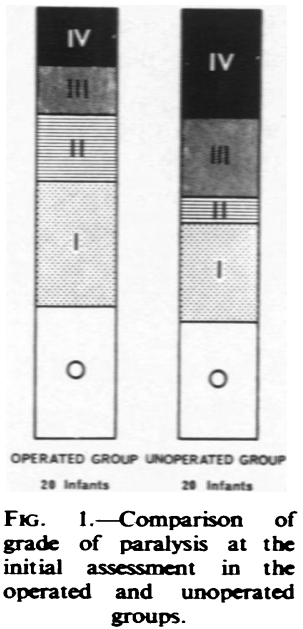

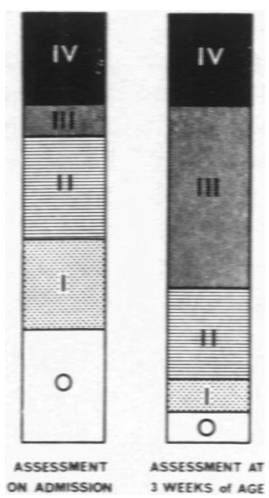

FiG. 2.-Grades of paralysis in 14 infants in the operated group at 3 weeks of age. compared with their initial assessment.

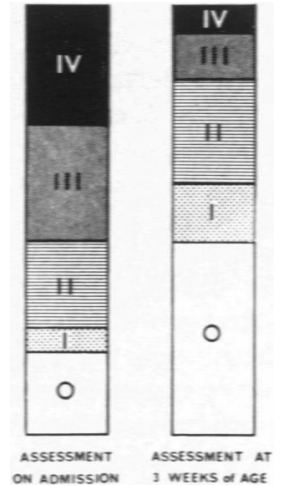

FIG. 3.-Grades of paralysis in 18 infants in the unoperated group at 3 weeks of age. compared with their initial assessment. muscles of the feet, which may possibly have been a little weak. Four days later, the only muscles that remained active were the hip flexors. Six months later, only the hip flexors were acting, but these had almost normal power. Another infant was first seen three hours after birth with almost normal lower limbs; 24 hours later no muscle activity was detected in either lower limb. On the seventeenth day of life there was only weak action in the hip adductor and flexor muscles in both limbs. On this day the myelomeningocele ruptured; it had been agreed that, should this occur, conservative treatment would cease, and immediate operative closure was performed. One week after that, the hip flexors, adductors, quadriceps and ankle dorsiflexors recovered. These muscles have remained active since then.

Figs. 4 and 5 show the initial and final assessment at 3 months of age in survivors. Of 10 children in the operated group, none was completely paralysed. The paralysis in seven children was of Grade III or IV, and they are potentially capable of independent walking. Two with Grade II paralysis may be able to walk after reconstructive operations and only one is severely paralysed. Of eight children in the unoperated group, only one is potentially capable of independent walking. Three are completely paralysed, three are severely paralysed, and one may walk independently after reconstructive operations.

Duration of Hospital Stay. Two patients in each group had a Holter valve inserted during the first admission for the treatment of their hydrocephalus. The surviving infants who were in the unoperated

group stayed almost twice as long in hospital as those in the operated group (Table 3). This represents a clear advantage for the operated infants, who had a better chance to avoid crossinfection in hospital and to return to the care of the mother.

\section{Discussion}

To obtain a more definite statistical conclusion by including more cases, the trial should have continued. The results, however, at this stage were already so striking, especially with regard to changes in muscle activity, that it was decided that it would be unethical to continue with the trial any further.

No series of cases with a detailed muscle assessment of this kind have been reported. The studies by Doran and Guthkelch (1961) and Guthkelch

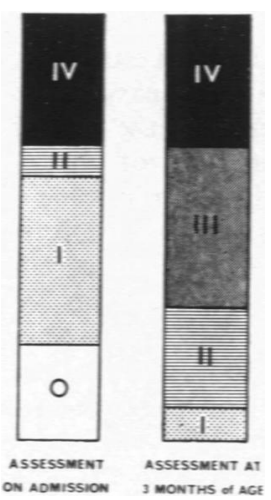

Fig. 4.-Grades of paralysis in 10 children in the oferated group at 3 months of age, compared with their initial assessment.

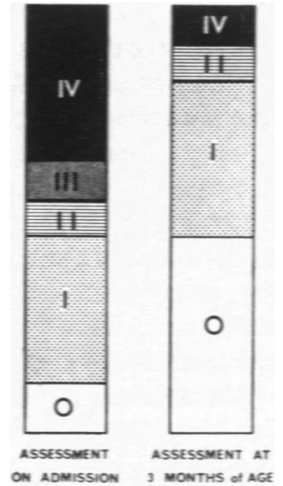

FiG. 5.-Grades of paralysis in eight children in the unoperated group at 3 months of age, compared with their initial assessment. 
(1962) were retrospective and did not conform to the pattern of a controlled trial. None of their operative closures were undertaken during the first $\mathbf{4 8}$ hours (A. N. Gutkelch, 1962, personal communication). Guthkelch's experience of patients operated upon after 48 hours but during the first week was not such a happy one. This seems to indicate that if operative closure is to be undertaken it should be done within the first 48 hours. It thus behoves those who first see the patient at birth-midwives, general practitioners and paediatricians-to regard a child with myelomeningocele as a surgical emergency requiring immediate transfer to a hospital equipped for the surgical closure of the spinal defect. Apart from the decreased mortality, lesser incidence of meningitis and improved muscle function, it should be noted that immediate closure does not increase the incidence of hydrocephalus. This is independent of the myelomeningocele and is present at birth (Lorber, 1961b).

The technical difficulties of closure of the myelomeningocele defect are very much less during the first $\mathbf{4 8}$ hours of life than they are at a later late. The absence of secondary oedema and fibrosis makes primary skin closure without resort to the fashioning of flaps possible in most cases, and the risk of damage to the spinal cord or nerve roots appears to be less, so that no patient in this series showed any evidence of loss of neurological function. The quality of skin cover that is usually achieved makes it possible to apply splints or plasters for orthopaedic purposes or operations more easily and without danger of ulceration of the myelomeningocele site.

The reasons for the greater mortality and incidence of meningitis and ventriculitis in the unoperated group are almost entirely to be found in the impossibility of maintaining sterility of a relatively large area of exposed and susceptible tissue until epithelialization has occurred. It is not so easy to account for the neurological deterioration in the unoperated patients. Drying out or infection of the neural plaque may account for deterioration in some cases, but they are unlikely to be the only or main factors in cases with a rapid onset of paralysis of a lower motor neurone type. This was seen in several patients and they were left with a permanent flaccid paralysis. One possible explanation for this phenomenon is that the tension that develops in the myelomeningocele as it fills with cerebro- spinal fluid after birth may cause traction on the nerve roots passing from the neural plaque to the periphery.

The improvement found in operated patients can be explained by assuming that in the course of transit from the uterus, a temporary neurapraxial type of lesion of spinal cord or nerve roots develops, and that these consequences can be reversed by immediate closure.

\section{Summary and Conclusion}

A controlled trial of immediate operative closure compared with no closure of myelomeningoceles in the napkin area in 40 newborn infants failed to disclose any advantage in conservative management provided that the closure was done within $\mathbf{4 8}$ hours of birth. The differences between the operated and the unoperated group were in favour of those treated by immediate operation as to mortality, local sepsis, meningitis and ventriculitis, muscle paralysis or duration of hospital stay. Muscle paralysis, in particular, diminished in many infants operated upon immediately, but increased in many treated conservatively. Although statistical analysis does not allow firm conclusions to be drawn about any single aspect of the analysis, summation of the trends in various aspects was sufficiently conclusive to us to make it ethically unjustifiable to continue the experiment and investigation further.

The main conclusion of the trial was that operative closure of a myelomeningocele should be regarded as a surgical emergency.

We are grateful to all paediatricians, obstetricians and general practitioners who referred the patients in this series to us. We acknowledge with thanks the help given to us by Dr. J. L. Emery and Mr. C. W. Potter, who supplied the pathological and bacteriological data: Professor R. S. Illingworth for some useful critical comments; and the Endowment Fund of the United Sheffield Hospitals for their grant to one of us (A.M.B.).

\section{REFERENCES}

Doran, P. A. and Guthkekch. A. N. (1961). Studies in spina bifida cystica. I. General survey and reassessment of the problem. cystica. I. General survey and reassessm
J. Neurol. Neurosurg. Psychiat., 24, 331.

Guthkekh, A. N. (1962). Studies in soina bifida cystica. II. When to repair the spinal defect. ibid., $25,137$.

Lorber, J. (1961 a). The diagnosis and management of hydrocephalus in infancy. N.Z. med. J., 60, 416.

(1961b). Systematic ventriculographic studies in infants born with meningomyelocele and encephalocele. The incidence and wevelopment of hydrocephalus. Arch. Dis. Childh., 36. 381 .

Medical Research Council (1942). Aids to the Investigation of Peripheral Nerve Injuries. War Memorandum No. 7. H.M.S.O., London.

Sharrard, W. J. W. (1962). The mechanism of paralytic deformity in spina bifida. Developm. Med. Child Neurol.. 4. 310. 